\title{
Possibility Using Camphene as Biorational Insecticide against the Red Palm Weevil Rhynchophorus ferrugineus (Colioptera: Curculionedae)
}

\author{
Aziza Sharaby $^{1}$, Mona EL-Dosary ${ }^{2}$ \\ ${ }^{1}$ Pests and Plant Protection Department, National Research Centre, Cairo, Egypt \\ ${ }^{2}$ Biology Department, Faculty of Education for Girls, EL-Kharj, Ryiadh, KSA
}

\begin{abstract}
The Red palm weevil, Rhynchophorus ferrugineus(RPW) (Coleoptera: Curculionidae) is the most important pest for the palm trees in all of the Arab Gulf area. The possible use of the terpene (Camphene) as toxic product alternative to chemical insecticide through the IPM program for controlling RPW and decreasing generating resistance phenomenon has been carried out, where there is a need for different compounds having different modes of action. Camphene is bicyclic monoterpene. It volatilizes readily at room temperature and has a pungent smell, is used in the preparation of fragrances and as a food additive for flavoring. Camphene is attractive for both male and female adults of the red palm weevil. Effect of camphene as fumigant or contact poison against different stages of Rhynchophorus ferrugineus (egg, $4^{\text {th }}$ instar larvae and adults) was determined, it cleared a toxic effect for all stages of the insect, especially for eggs and larvae as contact or fumigant poisons. $L C_{50}$ as contact poison was 249.2, 610.1and 777.3 $\mu \mathrm{l} . / 100 \mathrm{ml}$. , while $L C_{50}$ as fumigant poison was $34,47.9$ and $99.9 \mu l . / l$. air on egg, $4^{\text {th }}$ larval stage and adult respectively. Median lethal concentration (LC $C_{50}$ concentration) of camphene induced some biological changes on treated eggs and $4^{\text {th }}$ instar larvae.
\end{abstract}

Keywords: Red palm weevil, Rhynchophorus ferrugineus, camphene, terpene, toxicity, biological activity

\section{Introduction}

The red palm weevil (RPW)) Rhynchophorus frrugineus (Olivier.) (Coleoptera:Curculionidae) is a major pest of various palms in the Middle East, South and South East Asia, North Africa and Southern Europe (Nirula,1956). Females lay eggs in damaged or wounded plants. Upon hatching, the larvae burrow into the fresh tissue and migrate to the bud region and heart of the crown where they feed for two to four months and eventually kill the host plant (Abraham,1971). The RPW has a wide geographical and host range. It was reported to infest 40 palm species worldwide (Vidyasagar et al., 2000). Infestation with RPW starts with gravid females attracted to palm volatiles for laying eggs which hatch into damage inflicting larvae. Infestation date palms exhibit several symptoms depending on the stage of attack, e.g. oozing of brownish fluid mixed with palm tissue exerted by feeding larvae that has a typical fermented odor, tunneling of palm tissue by larval, presence of adults and pupae at the base of fronds, drying of infested offshoots, fallen pupae around an infested palm, drying of outer leaves niches and topping of trunk in case of sever and extensive tissue damage (Vidyasagar et al., 2000). Management of agricultural pests over the past half century has been largely depending on the use of synthetic pesticides for field and post-harvest protection of crops (Ferry et al., 2004). Several reviews on the control strategies including integrated pest management for RPW are available (Vidyasagar \& Subahanran, 2000). But the development of insect resistance to these products, the high operational cost and environmental pollution has created the need for developing of alternative approach to control many insect pests. In this sense, the usage of essential oils is an alternative to control many field and household insect pests (Sarawae et al., 2005; 2012; 2013). The essential oils are natural, volatile and complex compounds, and their characteristic odors are formed by secondary metabolites in plants. Many plant essential oils and their constituents from terpenes show a broad spectrum of activity against pest insects ranging from insecticidal, repellents, attractants, oviposition, deterrents, growth regulators and anti-vector activity (Bakkali et al., 2008). Plant essential oils and monoterpenes are shown as botanical pesticides. One of the most important features of botanical pesticides is to perform different effects on some insects. Most essential oil chemicals are relatively non-toxic to mammals and fish in toxicological tests, and introduce the criteria of reduced pesticides risk. Further, while resistance development continues to be an issue for many synthetic pesticides, it is likely that resistance will develop more slowly to essential oil based pesticides owing to the complex mixture of constituents that characterize many of these oils. Monoterpenes, the chemical constituents of essential oils found in plants, are known biologically active compounds. Essential oils and their constituents demonstrate fumigant and topical toxicity as well as antifeedant and repellent effects ( Shaya et al., 1997; Sharaby \& EL- Dosary 2014; Sharaby \& EL-Nugibal, 2015). Camphene is bicyclic monoterpene .It volatilizes readily at room temperature and has a pungent smell, is a minor constituent of many essential oils such as turpentine, cypress oil, camphor oil, nerol, ginger oil, and valerian. It is produced industrially by catalytic isomerization of more common $\alpha$-pinene. Camphene is used in the preparation of fragrances and as a food additive for flavoring. Its mid- $19^{\text {th }}$ century use as a fuel for lamps was limited by its explosiveness. Sharaby \& ELDosary, (2014 ) recorded that Camphene was attracted for 


\section{International Journal of Science and Research (IJSR) \\ ISSN (Online): 2319-7064 \\ Index Copernicus Value (2013): 6.14 | Impact Factor (2015): 6.391}

both sex of the RPW. The aim of the current research is to estimate the toxic effect of Camphene as contact or as fumigant toxicant on different stages of the red palm weevil, Rhynchophorus ferrugineus, and investigate the effect of $\mathrm{LC}_{50}$ of Camphene on some biological parameters to find their mode of action and its possible use as alternative natural material to chemical pesticide in the IPM program for controlling the insect. Studies have not yet been conducted to evaluate the insecticidal activities of monoterpene Camphene towards the RPW.

\section{Materials \& Methods}

\section{1- Insect culture and rearing conditions.}

The RPW culture was maintained in laboratory from larvae, pupae and adults collected from infested palm trees in AlKharj region of Saudi Arabia. The insect culture was established under laboratory condition at $25 \pm 2 \mathrm{C}^{\circ}$ temperature and $30 \% \mathrm{RH}$, and L: D10:14h. Sugarcane stem split longitudinally in $10 \mathrm{~cm}$, pieces to provide food source for (larvae and adult weevils) as well as oviposition substrate. From the laboratory bred pupae, the requisite number of emerging adults was collected. The adults after emergence from the pupae were sexed and maintained in separate $1 \mathrm{~L}$ jars with sugarcane pieces as food. Regular addition of fieldcollected adults to avoid inbreeding of the insects.

\section{2- Camphene: Obtained as a pure compound from Sigma Co. (St. Lous. Mo., U.S.A).}

\section{3- Fumigant toxicity}

Different concentrations of essential oil were prepared by dilution of oil $\mu 1 . / 100 \mathrm{ml}$. with distilled water, $0.1 \%$ Triton $\mathrm{X}$ 100 was added as emulsifier for different stages ( eggs, ${ }^{4 \text { th }}$ instar larvae and adult stage). They were applied on filterpaper (Whatman No.1) strip measuring $5 \mathrm{~cm}$ that attached to the lower side of the jars lid. Five normal and healthy adults 4days old were placed in empty 11. capacity glass Jar then sealed with air-tight glass lid. Thus, there was no direct contact between the oil and the insect. For the control jars, filter papers were treated with emulsifier and water only without the oil. Mortality was determined after $24 \mathrm{~h}$ from comment of the exposure time. Each test was replicated five times for each concentration or each tested stage. Signe of egg mortality indicated as no hatching, no motion of larvae and no leg or antennal movement observed for adult mortality.

\section{4- Contact toxicity}

Different tested stages ( eggs-, $4^{\text {th }}$ larval instar and 4days old adult ) were sprayed by the different concentrations of the oil emulsion using small plastic hand sprayer under open air and left to dry from moisture, then placed inside glass jar for mortality observation. An aqueous solution with the same amount of water and emulsifier used as in the treatment served as control. Each test repeated five time, 100 egg and 25 larvae or adult were used.

\section{5- Biological activity of Camphene on egg and $4^{\text {th }}$ larval instar.}

Concentration of the Camphene $\left(\mathrm{LC}_{50}\right)$ by fumigation or contact on egg stage and $4^{\text {th }}$ larval instars that determined from the previous test was prepared as emulsion in distilled water with two drops of Triton x100 (as emulsifier). Camphene emulsion was applied by fumigation or contact treatment as mentioned before, and then the hatched larvae from the treated eggs, and also the still living treated $4^{\text {th }}$ instar larvae were introduced on the normal Sugarcane stem split as a food source for follow-up growth and development. Different biological aspects were recorded as follows, larval duration, pupal duration, percentage pupation, and percentage of adult emergence adult longevity percentage of larval and adult deformation, percentage of deposited eggs / female, and percentage of egg hatching. Foregoing biological aspects was evaluated by daily observations.

6- Statistical analysis.

Data were corrected using Abbot's formula (Abbot, 1925) for the control mortality, then subjected to Probit analysis to estimate LC $_{50}$ values according to (Finny ,1971). The percentage of mortality was analysed using analysis of variance (ANOVA) test. Significant differences for means were compared using Duncan's multiple range test (Duncan, 1955) using computer software (SPSS, 1999). Significance between samples were indicated by probability values at $P<$ $0.05 \%$.

\section{Results \& Discussion}

Table 1 show a positive relation between Camphene concentration and percentage of mortality for all the tested stages of the RPW. Camphene has both contact and vapor phase activity, it was more effective by fumigation than as contact poison for all stages, $\mathrm{LC}_{50}$ was $34.1,46.9$ and $99.9 \mu \mathrm{l}$ oil/1. air by fumigation while it was $1249.2,610.1$ and 777.3 $\mu 1$. oil $/ 100 \mathrm{ml}$. water as a contact on egg, $4^{\text {th }}$ instar larvae and adult stage respectively. Egg was the most sensitive stage by fumigation followed by larvae then adults. Data cleared that Camphene have different effects on the insect, it block the air pore (egg micropyle in insect egg envelops or chorion) through which air oxygen enters, and cause egg asphyxiation.

Table 1: Toxicity of Camphene on different stages of Rhynchophorus ferrugineus by fumigation or contact treatments

\begin{tabular}{|c||c|c|c|c|c||c|c|c|c|c||}
\hline \multicolumn{1}{|c||}{ Tested Stage } & \multicolumn{5}{|c||}{ Fumigation $\mu \mathrm{L} / \mathrm{L}$} & \multicolumn{5}{c||}{ Contact $\mu \mathrm{L} / 100 \mathrm{ml}$} \\
\cline { 2 - 11 } & $\mathrm{LC}_{50}$ & $\mathrm{LC}_{95}$ & Slope $\pm \mathrm{SE}$ & $\mathrm{LM}$ & $\mathrm{UM}$ & $\mathrm{LC}_{50}$ & $\mathrm{LC}_{95}$ & $\mathrm{Slope} \pm \mathrm{SE}$ & $\mathrm{LM}$ & $\mathrm{UM}$ \\
\hline Egg & 34.1 & 296.9 & $1.8 \pm 0.3$ & 28.4 & 45.1 & 1249.2 & 3075.4 & $1.5 \pm 0.4$ & 199.1 & 377.5 \\
\hline $4^{\text {th }}$ larval instar & 46.9 & 100.9 & $5.1 \pm 0.5$ & 36.6 & 63.7 & 610.1 & 2689.4 & $2.6 \pm 0.4$ & 519.6 & 799.0 \\
\hline Adult & 99.9 & 8113.9 & $1.8 \pm 0.3$ & 839.3 & 1236.9 & 777.3 & 1785.9 & $4.6 \pm 0.7$ & --- & --- \\
\hline
\end{tabular}

Table 2 recorded very low number of egg hatching $26.7 \%$ after exposed to Camphene vapor, some of the hatched larvae still alive for 90 day then all died without reached the pupal stage in comparing with 27 day larval duration for control untreated test. $\mathrm{LC}_{50}$ of Camphene as contact treatment on eggs, also shows some biological aspects abnormalities 


\section{International Journal of Science and Research (IJSR) \\ ISSN (Online): 2319-7064}

Index Copernicus Value (2013): 6.14 | Impact Factor (2015): 6.391

where $13.3 \%$ of egg hatching was obtained, $6 \%$ of the hatched larvae reached to the pupal stage after 99.5 day. $30 \%$ of larval abnormalities was observed comparing with $10 \%$ for the control. All obtained pupae were small in size comparing with the control ones. All pupae died without reached the adult stage.

Table 2: Some biological aspects of Rhynchophorus ferrugineus after egg treatment with $\mathrm{LC}_{50}$ of Champhene by different methods

\begin{tabular}{|c|c|c|c|}
\hline Biological parameters & \multicolumn{3}{|c|}{$\begin{array}{c}\text { Control Camphene treatments } \\
\text { Fumigant Contact } \\
\text { mean } \pm \text { SD mean } \pm \text { SD mean } \pm\end{array}$} \\
\hline \% egg hatching & 26.7 & 13.33 & 98 \\
Larval duration & ---- & $99.5 \pm 0.44$ & $27 \pm 3.33$ \\
\% larval deformation & ---- & 30 & 10 \\
\% pupation & ----- & 6 & 88 \\
Pupal duration & ------- & ---- & $22 \pm 12.04$ \\
\% adult emergence & ------ & --- & 77 \\
\hline
\end{tabular}

(----) all died. No results.

Table 3 recorded some biological aspects of RPW after $4^{\text {th }}$ instar larvae treated with the $\mathrm{LC}_{50}$ of Camphene by the two different methods, as a contact poison all the treated $4^{\text {th }}$ instar larvae were died within 2.5 month without reached pupal stage, while as a fumigant poison, larval duration were significantly increased to 69.4 compared 23.5 day for the control. There were a great number of deformed larvae reached to $(24 \%)$, larva lost its motion and was unable to complete the molting process during the development. Great decrease in pupation percentage reached to $16 \%$ compared with $87.33 \%$ for the control normal larvae. No emerged adults were obtained, where deformed pupae and uncompleted adult in the form of pupal adult intermediate were noticed inside the pupal cocoons, for the control $72 \%$ emerged normal adults were obtained. It can be speculated that Camphene was toxic as fumigant or contact on all stages of RPW, it is potent $\mathrm{JH}$ mimic affecting the hormonal balance in RPW, resulting in strong suppression of embryogenesis, metamorphosis, and adult formation (Itaya, 1987 Kehler \& Peterson, 1991). Sharaby \& EL-Dosary (2014) mentioned that Camphene was attractive for both sex of RPW adults, with $60 \%$ percentage on males and with $40 \%$ on females. Camphene have different effects on the insect and the most important is that they block the air holes (Spiracles) through which the insect breathes, and causes asphyxiation. ALSharook et al. (1991) recorded that the oil effects on the insect respiratory and nervous system leading to insect death, disrupt the normal hormone regulation. In some cases oils also may act as poisons, interacting with the fatty acids of the insect and interfering with normal metabolism. Some researches have demonstrated that essential oils have neurotoxic, cititoxic and mutagenic action among others in different organism, and the essential oils act as multiple levels in the insect, so the possibility of generating resistance is little probable (Bakkali et al., 2008). Won-II et al. (2003) mentioned that insects response varied according to oil type, dose and developmental stage. Oils work primarily by covering and suffocating the pest. In some cases, they can disrupt certain membranes of exoskeleton (Cranshaw \& Baxendale, 2014). Henandez-Lambrano et al, (2015) mentioned that the essential oils extracted from the citronella genus (Cymbopogon) can be used to control Oryzaephelius surinamensis (L.) and maize weevil Sitopholus zeamaiz Motsch. It can also reduce the risk associated with the use of synthetic insecticides. Turpentine oil is a type of essential oil that is extracted from turpentine (Saeidnia, 2014). The main component includes $\alpha$ - thujenene, $\alpha$-pinene, camphene, $\beta$ pinene, myrecene, 3-carene, p-cymene, limonene, and $\beta$ phyllandrene among several others (Liu et al., 2013). Regnault-Roger \& Hamraoui, (1995) recorded that the point of entry of the toxin is one of apart from the variability of phytochemical patterns that involves several factors. Commonly terpene oil can be inhaled, ingested or skin absorbed by insects. The fumigant toxicity of essential oils and their main components, the volatile monoterpenes, has been described (Weaver et al., 1991; Regnault-Roger et al., 1993). The present results from this study agreed also with that recorded by Sarwar \& Salman, 2015 that many plant essential oils and their constituents of monoterpenes show a broad spectrum of activity against insect pests, these natural chemicals have multiple mode of action, including antifeedant and repellent activity, moulting and respiration inhibition, growth and fecundity reduction and cuticle disruption, and can act as contact, fumigant, and oviposition inhibition toxicant. These multiple mode of action are advantageous because they delay the development of resistance among arthropod pest population.

Table 3: Some biological aspects of Rhynchophorus ferrugineus after $4^{\text {th }}$ larval instar treatment with $\mathrm{LC}_{50}$ of Champhene by different methods .

\begin{tabular}{|c|c|c|c|}
\hline Biological parameters & \multicolumn{3}{|c|}{$\begin{array}{c}\text { Control Champhene treatments } \\
\text { Fumigant Contact }\end{array}$} \\
& mean \pm SD mean \pm SD mean \pm SD \\
\hline Larval duration & $69.4 \pm 0.54$ & ---- & $23.5 \pm 7.9$ \\
\% larval deformation & 24 & ---- & 12 \\
\% pupation & 16 & ---- & 87.33 \\
Pupal duration & ----- & ----- & $22 \pm 12.04$ \\
\% adult emergence & ---- & ---- & $72 \%$ \\
& & & \\
\hline
\end{tabular}

(-----) all died

\section{Conclusion}

From all these results, it could be deduced that terpene Champhene present a widespread range of activities on $R$.ferrugineus as contact or fumigant poison, it works on the endocrine system and therefore on the enzyme system of adults. Champhene could be used for environmentally safer pest management option. It is active against all stages of the insect as contact and as fumigant poison. Possibility of generating resistance is little probable, and can be effectively used as part of current alternative integrated pest management strategies of R.ferrugineus aiming at decreasing the use of classical insecticides, ecochemical control based on plant- insect interaction relationships is one of the most promising methods.

\section{References}

[1] Aввотт ,W. S. A. 1925. Method for computing the effectiveness of an insecticide J. Econ. Entomol,18: 265.

[2] ABRAHAM ,V.A. 1971. Note on an effect method of preventing entry by red weevil Rhynchophorus 


\section{International Journal of Science and Research (IJSR) \\ ISSN (Online): 2319-7064}

Index Copernicus Value (2013): 6.14 | Impact Factor (2015): 6.391

ferrugineus into the stem of Coconut palm through cut petioles . Indian J. Agric. Scie., 41: 1130-1131.

[3] AL- Sharook , Kabala, Z., Jiang, Y ., Rembold, H. .1991. Insect growth inhibitors from two tropical Meliaceae: Effects of crude seed extracts on mosquito larvae. J. Appl. Entomol., 111: 425- 530.

[4] Bakkali, F., Averbeck, S., Averbeck, S., IdaOmar., M. 2008. Biological effects of essential oils A review. Journal of Food and Chemical Toxicology, 46: 446- 475. CRANSHAW W.S., B BAXENDAL.2014. Insect control: Horticultural oils, In . Colorado State University Extension No. 5. 569.

[5] DunCAN, D.B. 1955. Multiple range and multiple $F$ tests. - Biometrics, 11:1-42

[6] FInNeY D.J. 1971. Probit analysis. - Cambridge Univ. Press, Cambridge, 333 pp.

[7] Ferry N., Edwards, M. G ., Gatehouse, J.A ., GATEHOUSE, A.M. 2004. Plant insect interaction: Molecular approaches to insect resistance- In Sasaki, T., Christou, P.(Eds). - Biotechnol., 15: 155- 161.

[8] Hernandez-Lambrano, R., Pajaro-Castro, N., Caballero-Gallardo, K., Stashenko., E., OliveroVERBEL, J. 2015. Essential oils from plants of genus Cymbopogon as natural insecticides to control stored product pests. J. Stored Prodt Res, 62: 81-83.

[9] KOEHLERP, G., JPATTERSON, R. 1991. Incorporation of pyriproxyfen in German cockroach( Dictyoptera: Blattellidae) management program. J. Econ.. Entomol , 84:917-921

[10] LIU, L.X., LIANG, L.C., CHIN, F. 2013. Indonesia turpentine chemical analysis. Interpret. Scie \& Technol. Division, 13: 28-30.

[11] NIRULA, K.K. 1956. Investigation on the pests of coconut palm, Part-IV. Rhynchophorus ferrugineus. Indian Coconut J., 9: 229- 247.

[12] Regnault-Roger, C. 1997. The potential of botanical essential oils for insect pest control. Integr. pest manage review, 2: 25- 34.

[13] SARWAR , M. 2015. Usage of biorational pesticide with novel modes of action; Mechanism and application in crop protection. Intern. . Materials Chemist \&Physic, 1(2): $156-1620$

[14] SARWAR , M., SALMAN, M. . 2015. Toxicity of oils formulation as a new useful tool in crop protection for insect pests control. Intern.. J. Chem. \& Biomolecular Science, 1 (4): 297-302.

[15] SARWAR, M., ASHFAQ, M ., AhMAD, A ., RANDHAWA, M.A.M . 2013. Assessing the potential of assorted plant powders on survival of Caloglyphus grain mite ( Acari: Acaridae) in wheat grain. Intern. . Agric. Science \& Bioresource Engineering Res, 2 (1): 106.

[16] Sarwar , M., AhMAd, N ., BuX, M., Tofique, M . 2012. Potential of plant materials for management of Cowpea bruchid Callosobruchus analis ( Coleoptera: Bruchidae) in gram Cicer arietinum during storage. The Nucleus, 49(1):61- 64.

[17] Sarwar, M., Ali , A Ahmad, ., N., TOFiQue, M. 2005. Expediency of different botanical products intended for managing the population of rice stem borers . Proce, $25^{\text {th }}$ Pkistan Conger. Of Zoology, March 1-3, Sindh Agriculture University, Tandojam, 25: 15- 23.

[18] SHARABY, A., AL-DoSARY, M. 2014. An electric air flow olfactometer and the olfactory Response of
Rhynchophorous ferrugineus Weevil to Some Volatile Compounds. J.Agric.\& Ecology Research International, 1(1): 40-50 .

[19] Sharaby , A., EL-NuJiBAn, A. 2015. Biological activity of essential oil of Sage Plan leaves Salvia offecinalis L. against the black cutworm Agrotis ipsilon (Hubn.). Intern. J. Science \& Resh (IJSR), 4(5):737741.

[20] ShaAyA , E., KostJUKOVSKI, M., EILberG, J., SURKPRAKARN, C. 1996. Plant oils as fumigant and contact insecticides for the control of stored product insects. . Stored Prod. Res., 33: 7-15.

[21] SPSSInc. 1999. Statistical package for social science, Version 10., SPSS Inc, USA.

[22] Vidyasagar, P.S.P.V., Subaharan, K. 2000. Role of behavior modifying chemicals in management of key pests of palm, pp. 121-126. In. Innovative pest and disease management in horticultural and plantation crop- Narsimhan S., G Suresh., S.D Wesley., Eds)., SPIC Science Foundation, Chennai, The British Council, The British Deputy High Commission, Chennai, India.

[23] VidyASAGAR, P.S.P.V., AL-SAIHATI, . A.A., ALMohanna, O.E ., SubBel, A.I., AbDul-Mohsin, A.M. 2000. Management of red palm weevil Rhynchophorus ferruguneus Olivier, a serious pest of date palm in ALQatif, Kingdom of Saudi Arabia. J.1 Plantation Crop, 28(1): 35- 43.

[24] Won-II , C., Eun-HeE L., ByeOUnG-RyeOL, C., Hyung-MAN, P., Young-JoON, A . 2003. Toxicity of plant essential oils to Trialeurodes vaporariorum ( Homoptera: Aleyrodidae). J. Econ. Entomol., 96 (5): 1479-1484. 